Microwave-induced titanate nanotubes and the corresponding behaviour after thermal treatment

This article has been downloaded from IOPscience. Please scroll down to see the full text article. 2007 Nanotechnology 18175702

(http://iopscience.iop.org/0957-4484/18/17/175702)

The Table of Contents and more related content is available

Download details:

IP Address: 140.112.113.225

The article was downloaded on 16/12/2008 at 06:27

Please note that terms and conditions apply. 


\title{
Microwave-induced titanate nanotubes and the corresponding behaviour after thermal treatment
}

\author{
Hsin Hung Ou, Shang Lien Lo ${ }^{1}$ and Ya Hsuan Liou \\ Environmental Pollution Prevention and Control Technology, Graduate Institute of \\ Environmental Engineering, National Taiwan University, 71 Chou-Shan Road, Taipei, \\ Taiwan 106, Republic of China \\ E-mail: sllo@ntu.edu.tw (Shang Lien Lo)
}

Received 19 January 2007, in final form 5 March 2007

Published 2 April 2007

Online at stacks.iop.org/Nano/18/175702

\begin{abstract}
This study attempts to survey the influence of microwave irradiation on the characterizations of titanate nanotubes (TNTs) synthesized by microwave hydrothermal treatment (M-H treatment). Based on the performance of specific surface areas determined by the classic Brunauer-Emmett-Teller method $\left(S_{\mathrm{BET}}\right)$, TNTs synthesized at $130{ }^{\circ} \mathrm{C}$ for $1.5 \mathrm{~h}$ with and without $400 \mathrm{~W}$ irradiation presented $S_{\mathrm{BET}}$ values of 256 and $76 \mathrm{~m}^{2} \mathrm{~g}^{-1}$, respectively. The result indicates that the formation kinetics of TNTs is significantly enhanced by $\mathrm{M}-\mathrm{H}$ treatment. The microwave-induced TNTs are preferentially assigned for $\mathrm{Na}_{x} \mathrm{H}_{2-x} \mathrm{Ti}_{3} \mathrm{O}_{7}$ structure and the $\mathrm{Na} / \mathrm{H}$ ratio appreciably increases with higher irradiation power. Regarding the behaviour of TNTs after thermal treatment, TNTs synthesized under $70 \mathrm{~W}$ presented anatase phase at $500{ }^{\circ} \mathrm{C}$ through rearrangement and restacking of $\left[\mathrm{TiO}_{6}\right]$. Anatase-to-rutile transformation subsequently occurred at $700^{\circ} \mathrm{C}$. TNTs synthesized under 400 and $700 \mathrm{~W}$ presented a rod shape at $700^{\circ} \mathrm{C}$. The rod shape mainly comprise of $\mathrm{Na}_{2} \mathrm{Ti}_{6} \mathrm{O}_{13}$ of which the $\left(\mathrm{Ti}_{3} \mathrm{O}_{7}\right)^{2-}$ layers with the topotactical connection proceed to form $\left(\mathrm{Ti}_{6} \mathrm{O}_{13}\right)^{2-}$ along the [110] direction during the thermal process.
\end{abstract}

(Some figures in this article are in colour only in the electronic version)

\section{Introduction}

Many efforts have been dedicated to the synthesis of titanate nanotubes (TNTs), including those using the template method [1], the sol-gel process [2], anodic oxidation [3], and hydrothermal treatment [4-6]. Hydrothermal treatment received particular attention owing to the cost-effective and easy way of obtaining well-structured TNTs. Temperature applied, reaction time, and pressure are the predominant factors in the formation process of TNTs [7]. The conventional hydrothermal treatment (C-H treatment) seems favourable for the formation of TNTs for their excellent morphology. However, the process always requires as long as $20 \mathrm{~h}$ to achieve highly crystalline TNTs $[4-6,8]$. So far, a few efforts have focused on the rapid kinetics of the formation of TNTs

\footnotetext{
1 Author to whom any correspondence should be addressed.
}

in hydrothermal treatment. Some researchers have proposed a technology coupled with sonication and hydrothermal treatment for which the synthesis duration is shortened from 20 to $4 \mathrm{~h}[9,10]$. Besides, Wu et al [11] have discovered that the TNT structure can be achieved within a shorter synthesis duration (90 min) under $195 \mathrm{~W}$ microwave irradiation power. Although they have demonstrated an enhanced performance in synthesizing TNTs with the aid of microwave irradiation, their study did noit consider the effect of irradiation power on the characterizations of synthesized TNTs. Particularly, the adjustment and control of the synthesis temperature were not considered, which has been deemed to be the most important and critical parameter in synthesizing TNTs.

The thermal stability of TNTs synthesized by $\mathrm{C}-\mathrm{H}$ treatment has also been extensively investigated. The sintering protonated form of TNTs at a temperature higher than 
$500{ }^{\circ} \mathrm{C}$ presents fibrous morphology with anatase phase [12] while Sun and $\mathrm{Li}$ [13] have indicated that a sodiumsaturated form of TNTs is stable up to $850{ }^{\circ} \mathrm{C}$. Systematic studies concerning the phase transformation of TNTs at elevated temperatures have also been reported [14]. The thermal stability and morphological transformation of TNTs during the sintering process have also been confirmed to be dependent on the $\mathrm{Na}$ amount within the TNT structure $[15,16]$. This study, therefore, attempts to synthesize TNTs by microwave hydrothermal process (M-H process) and to investigate the corresponding characterizations of TNTs induced by microwave irradiation. The influence of post-thermal-treatments on the synthesized TNTs was also surveyed, including thermal stability, phase, and morphology transformation at progressively elevated temperatures (100$\left.700{ }^{\circ} \mathrm{C}\right)$.

\section{Experiment}

The microwave digestion system (Ethos Touch Control, MILESTONE Corporation), with a double-walled vessel consisting of an inner Teflon liner and outer shell of high strength Ultem polyetherimide, was used. During the M-H process, the applied temperature, irradiation power lever, as well as time of treatment, were computerized. An auxiliary cooling/heating device is fitted to the system, which enables the system to operate at a fixed temperature for a longer time while maintaining the input power of microwave irradiation during the reaction. A solution of $70 \mathrm{ml}$ of $10 \mathrm{M} \mathrm{NaOH}$ coupled with $600 \mathrm{mg} \mathrm{\textrm {TiO } _ { 2 }}$ (Degussa P25) was transferred to the Teflon container of the double-walled vessel. The prepared samples were treated at different temperatures $(110,130,150$, and $\left.175^{\circ} \mathrm{C}\right)$, microwave power $(70,200,400$, and $700 \mathrm{~W})$, and durations $(1.5,3,6$, and $12 \mathrm{~h})$. After the M-H process, the resulting powders were washed by mixing three times with $0.5 \mathrm{M} \mathrm{HCl}$ followed by washing five times with deionized water. Subsequently, TNTs can be obtained after filtration and drying under the conditions of $-60.2^{\circ} \mathrm{C}$ and $100-200$ mTorr for $12 \mathrm{~h}$. The post-thermal-treatments of as-synthesized TNTs were conducted in a tubular oven under the condition of $80 \%$ $\mathrm{N}_{2} / 20 \% \mathrm{O}_{2}$ at progressively elevated temperatures (100, 300, 500 , and $700^{\circ} \mathrm{C}$ ) for $2 \mathrm{~h}$.

Specific surface areas of samples determined by the Brunauer-Emmett-Teller method $\left(S_{\mathrm{BET}}\right)$ were measured at $-196^{\circ} \mathrm{C}$ with an automated gas adsorption analyser (Micromeritics ASAP 2010). The phase identification of TNTs was conducted with powder X-ray diffraction (XRD) equipped with $\mathrm{Cu} \mathrm{K} \alpha$ radiation (MAC Science-MXP18). A fieldemission scanning electron microscope (FE-SEM) equipped with energy dispersive $\mathrm{x}$-ray spectroscopy (JEOL JSM-6500F) and high-resolution transmission electron microscopes (HRTEM; FEI Tecnai G2; JEOL JEM-3000F) were used to investigate the morphology and the structure of the TNTs. The structures of TNTs and sodium titanate demonstrated in the manuscript were constructed by the Ca.R.Ine version 3.1 crystallography program package.

\section{Results and discussion}

The research preliminarily surveyed the formation of TNTs based on the performance of $S_{\mathrm{BET}}$ while $S_{\mathrm{BET}}$ of a titanium

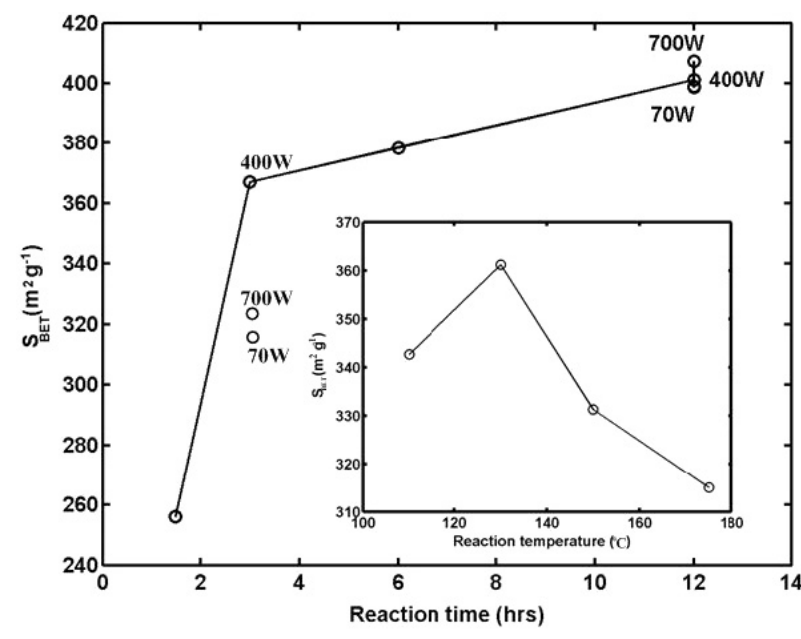

Figure 1. $S_{\mathrm{BET}}$ of TNTs synthesized at different conditions. (The obtained $S_{\mathrm{BET}}$ of TNTs in the diagram were synthesized at $130{ }^{\circ} \mathrm{C}$ for different reaction periods and microwave irradiation power; the obtained $S_{\mathrm{BET}}$ of TNTs in the insert were synthesized at different synthesis temperatures for $3 \mathrm{~h}$ under $400 \mathrm{~W}$ microwave irradiation.)

source (Degussa P-25) fall into the range of $50 \pm 1.5 \mathrm{~m}^{2} \mathrm{~g}^{-1}$. Figure 1 demonstrates that the prolonged reaction time $(12 \mathrm{~h})$ and optimum temperature $\left(130^{\circ} \mathrm{C}\right)$ were beneficial to the formation of TNTs. The optimum synthesis temperature $\left(130^{\circ} \mathrm{C}\right)$ in synthesizing TNTs by $\mathrm{M}-\mathrm{H}$ treatment is the same as that by $\mathrm{C}-\mathrm{H}$ treatment, which was reported by Tsai and Teng [5]. TNTs synthesized at $130^{\circ} \mathrm{C}$ within $1.5 \mathrm{~h}$ under $400 \mathrm{~W}$ led to the corresponding $S_{\mathrm{BET}}$ of $256 \mathrm{~m}^{2} \mathrm{~g}^{-1}$, while $S_{\mathrm{BET}}$ of TNTs obtained without the presence of microwave irradiation was $76 \mathrm{~m}^{2} \mathrm{~g}^{-1}$. This result indicates that the TNT structure is appreciably achieved with the aid of microwave irradiation within shorter reaction times. The effect of microwave irradiation on the performance of $S_{\mathrm{BET}}$ seems trivial while the synthesis reaction time was prolonged to $12 \mathrm{~h}$ (figure 1). In order to facilitate a more explicit discussion concerning the effect of microwave irradiation on the characterizations of TNTs, TNTs synthesized at $130^{\circ} \mathrm{C}$ for $3 \mathrm{~h}$ under 70, 400, and $700 \mathrm{~W}$ were chosen as the targets for the following investigations. In the following materials, they are abbreviated as TNTs-70 W, TNTs-400 W, and TNTs-700 W, respectively.

There are vague but identifiable rutile phase peaks in the XRD spectra, while no vivid anatase phase is present in TNTs (figure 2). This phenomenon provides support for the anatase phase with higher surface energy to be the preferred phase in synthesizing TNTs [5, 15, 17]. The result also indicates that the rutile phase possesses higher stability and gradually gets involved in aiding reaction to achieve high $S_{\text {BET }}$. Based on the following discussions concerning XRD patterns, HR-TEM results, and even the dynamic behaviour of TNTs after thermal treatment, peaks appearing at the diffraction angles of $9.58^{\circ}, 24.01^{\circ}, 28.68^{\circ}$, and $48.23^{\circ}$ are preferentially assigned for trititanate $\left(\mathrm{Na}_{x} \mathrm{H}_{2-x} \mathrm{Ti}_{3} \mathrm{O}_{7}\right)$ despite some debate over the crystal structure of TNTs, which is among the following: $\mathrm{H}_{2} \mathrm{Ti}_{3} \mathrm{O}_{7}[8,18,19], \mathrm{Na}_{x} \mathrm{H}_{2-x} \mathrm{Ti}_{3} \mathrm{O}_{7}[13,15,20]$, $\mathrm{Na}_{x} \mathrm{H}_{2-x} \mathrm{Ti}_{2} \mathrm{O}_{5}\left(\mathrm{H}_{2} \mathrm{O}\right)[6,18,21]$, and $\mathrm{H}_{2} \mathrm{Ti}_{4} \mathrm{O}_{9}\left(\mathrm{H}_{2} \mathrm{O}\right)$ [22]. Accordingly, TNTs synthesized via the $\mathrm{M}-\mathrm{H}$ process exist in 


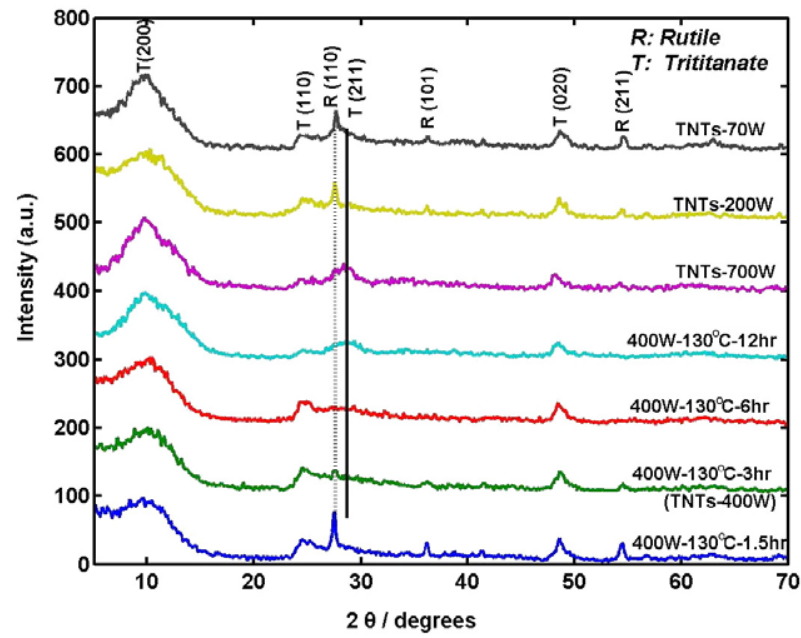

Figure 2. The dependence of XRD patterns for synthesized TNTs on the synthesis duration and applied irradiation power.

a monoclinic system, of which the structure is the same as if constructed by the three $\left[\mathrm{TiO}_{6}\right]$ octahedra as the basic structural units $[13,18,19]$.

Regarding the obtained XRD patterns, the peaks appearing at $27.43^{\circ}$ were assigned for the response of the rutile phase (dotted line, figure 2) instead of the TNT phase because of the decreasing intensity with the prolonged reaction time. While prolonging the reaction time to 6 and $12 \mathrm{~h}$, the TNT phase dominates at a diffraction angle of $28.68^{\circ}$ (solid line, figure 2). The relatively lower intensity of the rutile phase can also be observed for the TNTs synthesized under high irradiation power. In other words, the diffraction pattern of TNTs- $700 \mathrm{~W}$ exhibits an obvious peak at $28.68^{\circ}$, again evidence that the formation of TNTs can be achieved within short reaction duration with the aid of microwave irradiation. The appearance of a peak at $28.68^{\circ}$ also indicates abounding $\mathrm{Na}$ atoms intercalating within the structure of TNTs. A similar feature in XRD patterns of non-acid and acid-washed TNTs has been found in the previous research [13, 15, 23]. As seen in figure 2, this peak is more apparent for TNTs-700 W than for TNTs-400 $\mathrm{W}$ and TNTs-70 $\mathrm{W}$. That suggests high irradiation power is beneficial to the intercalation of $\mathrm{Na}$ atoms into TNT structure. Furthermore, $\mathrm{Na}$ atoms within the TNT structure are believed to enlarge the spacing between interlayers [15] for which the interlayer spacing is generally taken as the response of the $d$-spacing of (200) planes in $\mathrm{H}_{2} \mathrm{Ti}_{3} \mathrm{O}_{7}$ [20]. Based on the XRD patterns, the calculated $d_{200}$ values of TNTs$70 \mathrm{~W}, 400 \mathrm{~W}$, and $700 \mathrm{~W}$ are 8.217, 8.673, and $8.988 \AA$, respectively. The trend can be supported by the observation of HR-TEM images in the cases of TNTs-70 W and TNTs$700 \mathrm{~W}$, for which their interlayer spacings are 8.39 and $8.71 \AA$, respectively (figures 3(a) and (b)). In fact, there exists a discrepancy for interlayer spacing between the XRD results and the observation of HR-TEM which may result from some defects and impurities within the structure of TNTs [18].

In terms of thermal treatment on the microwave induced TNTs, no vivid change was found in XRD patterns until the sintering temperature was raised to $500{ }^{\circ} \mathrm{C}$. Figure 4 show the XRD patterns of TNTs-70 W, $-400 \mathrm{~W}$, and $-700 \mathrm{~W}$

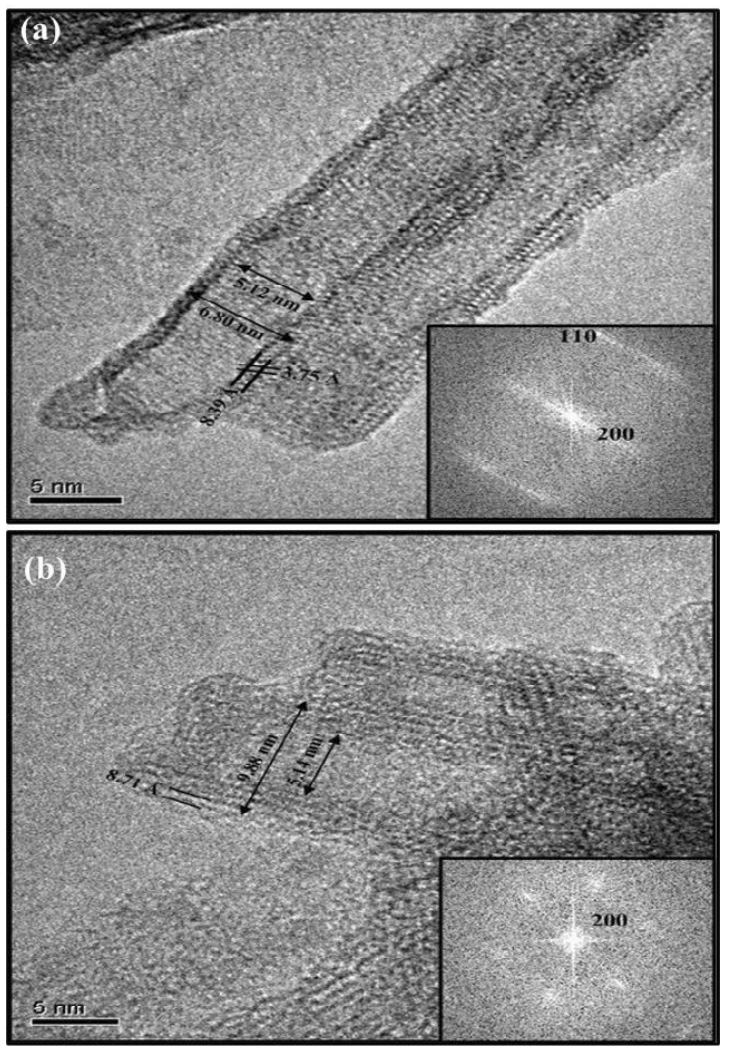

Figure 3. HR-TEM and Fourier transform images of (a) TNTs-70 W and (b) TNTs-700 W.

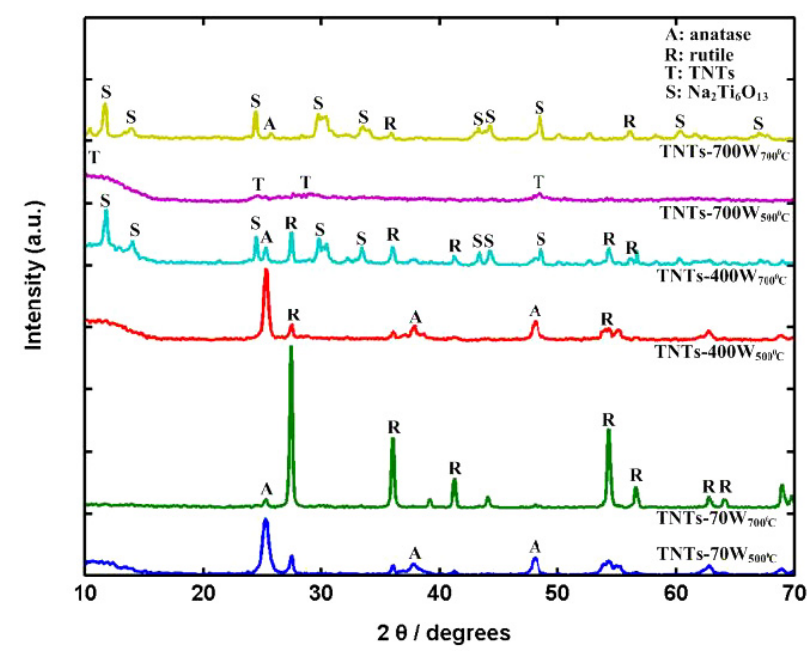

Figure 4. XRD patterns of (a) TNTs-70 W, (b) TNTs-400 W, and (c) TNTs- $700 \mathrm{~W}$ sintered at 500 and $700^{\circ} \mathrm{C}$.

sintering at 500 and $700{ }^{\circ} \mathrm{C}$. As seen in figure 4 , TNTs-70 W became more crystalline with a dominant anatase phase at $500{ }^{\circ} \mathrm{C}$. The transformation of the metastable anatase phase to the significant rutile phase was found at $700^{\circ} \mathrm{C}$, well below the transformation temperature of $900^{\circ} \mathrm{C}$ reported for TNTs synthesized by C-H treatments [5]. The observations in XRD patterns of TNTs- $70 \mathrm{~W}_{500}{ }^{\circ} \mathrm{C}$ and TNTs- $700 \mathrm{~W}_{500}{ }^{\circ} \mathrm{C}$ indicate that the thermal stability of TNTs-70 W is weaker than that of 


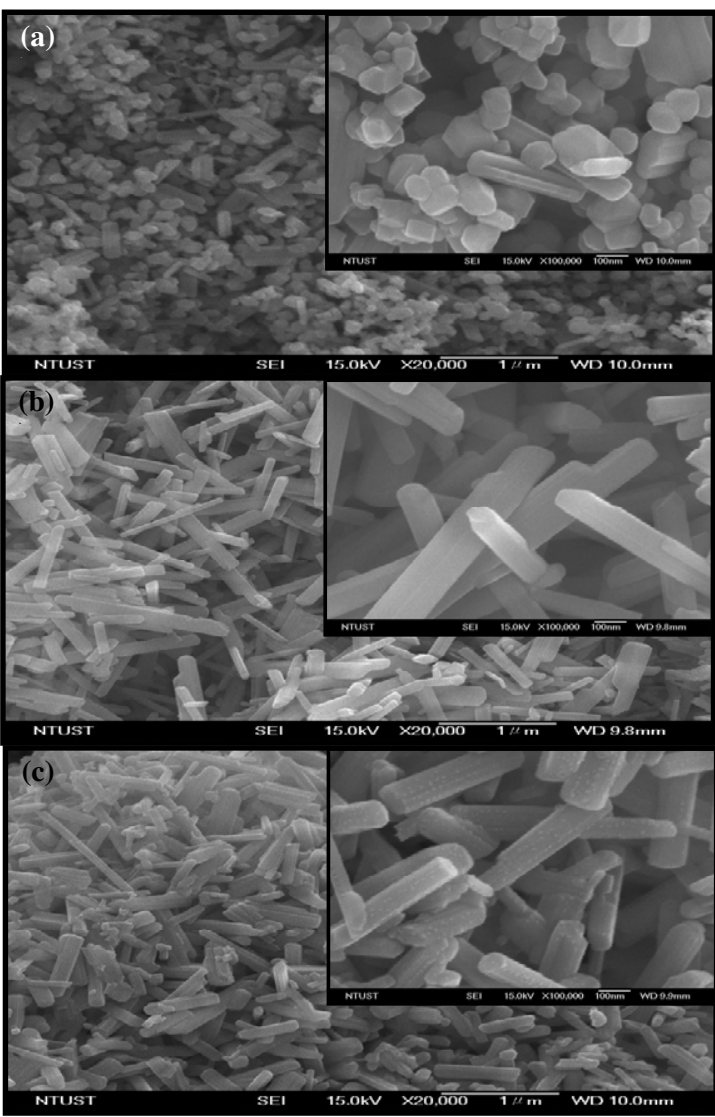

Figure 5. FE-SEM images of (a) TNTs-70 W, (b) TNTs-400 W, (c) TNTs- $700 \mathrm{~W}$ sintered at $700^{\circ} \mathrm{C}$ for $2 \mathrm{~h}$.

TNTs-700 W. The phenomenon is consistent with the results reported by previous researchers that the intercalating $\mathrm{Na}$ atoms aid the thermal stability of TNTs [15]. In the case of TNTs-400 W, the same behaviour can be observed where the significant anatase appears at the sintering temperature of $500{ }^{\circ} \mathrm{C}$. A further increase in temperature to $700{ }^{\circ} \mathrm{C}$ results in the crystallization of $\mathrm{Na}_{2} \mathrm{Ti}_{6} \mathrm{O}_{13}$, and the phase transformation from anatase to rutile begins. TNTs- $700 \mathrm{~W}$ samples sintering at $700{ }^{\circ} \mathrm{C}$ resulted in the mixture of abundant $\mathrm{Na}_{2} \mathrm{Ti}_{6} \mathrm{O}_{13}$ and trace amounts of anatase and rutile phases. Accordingly, TNTs synthesized under higher microwave irradiation would lead to a diminishing appearance of the anatase phase and enhancement of the relative intensity of $\mathrm{Na}_{2} \mathrm{Ti}_{6} \mathrm{O}_{13}$ after thermal treatment. Obvious changes in morphology for TNTs-70 W, $-400 \mathrm{~W}$, and $-700 \mathrm{~W}$ after thermal treatment of $700{ }^{\circ} \mathrm{C}$ were also observed, as demonstrated in figures 5(a)-(c), respectively. A great number of granular crystals were formed with a trace number being rod-shaped (figure 5(a)), while figures 5(b) and (c) present homogeneous rod morphology. The corresponding $\mathrm{Na} / \mathrm{Ti}$ atomic ratios analysed by EDX are $0,0.326$, and 0.518 , respectively, which corresponds to the fact that the higher irradiation power favourably drives $\mathrm{Na}$ atoms to intercalate into the structure of TNTs.

Regarding the crystal growth of TNTs-70 W after thermal treatment, the anatase $\mathrm{TiO}_{2}$ very likely generate because of the thermal condensation of $\mathrm{H}_{2} \mathrm{Ti}_{3} \mathrm{O}_{7}$. The zigzag ribbons of $\left(\mathrm{Ti}_{3} \mathrm{O}_{7}\right)^{2-}$ layers have to be settled into detached $\left[\mathrm{TiO}_{6}\right]$ of (a)

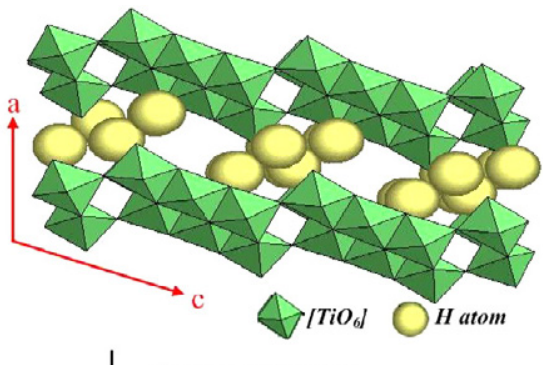

$\downarrow$ Rearrangement

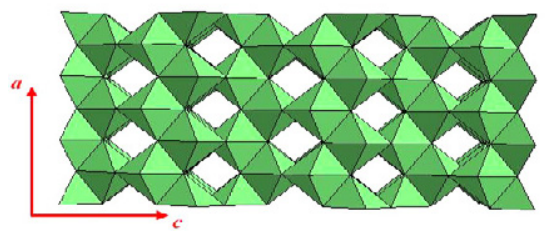

(b)

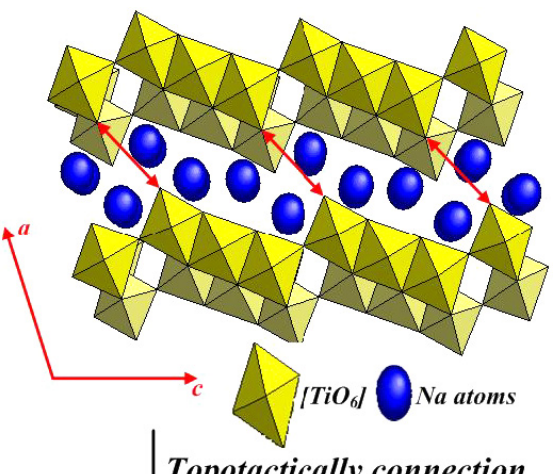

Topotactically connection

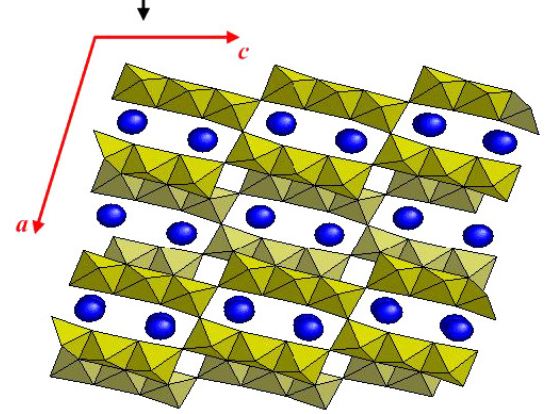

Figure 6. Hypothetical scheme projected along the [010] direction for the transformation of TNTs after post-thermal-treatments (a) from $\mathrm{H}_{2} \mathrm{Ti}_{3} \mathrm{O}_{7}$ to anatase $\mathrm{TiO}_{2}$ for TNTs-70 W, (b) from $\mathrm{Na}_{2} \mathrm{Ti}_{3} \mathrm{O}_{7}$ to $\mathrm{Na}_{2} \mathrm{Ti}_{6} \mathrm{O}_{13}$ for TNTs-700 W.

which each $\left[\mathrm{TiO}_{6}\right]$ octahedron is essential to rearrange and subsequently form anatase $\mathrm{TiO}_{2}$, as indicated in figure 6(a). Further increasing the sintering temperature to $700^{\circ} \mathrm{C}$, TNTs$70 \mathrm{~W}$ followed the anatase-to-rutile transformation proposed by Gouma et al $[24,25]$ in that the newly formed rutile crystals occurred at the expense of neighbouring anatase grains. The growth of rutile needs interaction between the existing rutile particles and the surrounding anatase particles. This theory is consistent with the aforementioned results that show that TNTs-70 W possess a more abundant rutile phase than TNTs$400 \mathrm{~W}$ and TNTs- $700 \mathrm{~W}$, as indicated in figure 2.

Rod formation occurred exclusively from TNTs-400 W and TNTs-700 W, which is believed to require anisotropic crystal growth owing to the difference of the surface free 


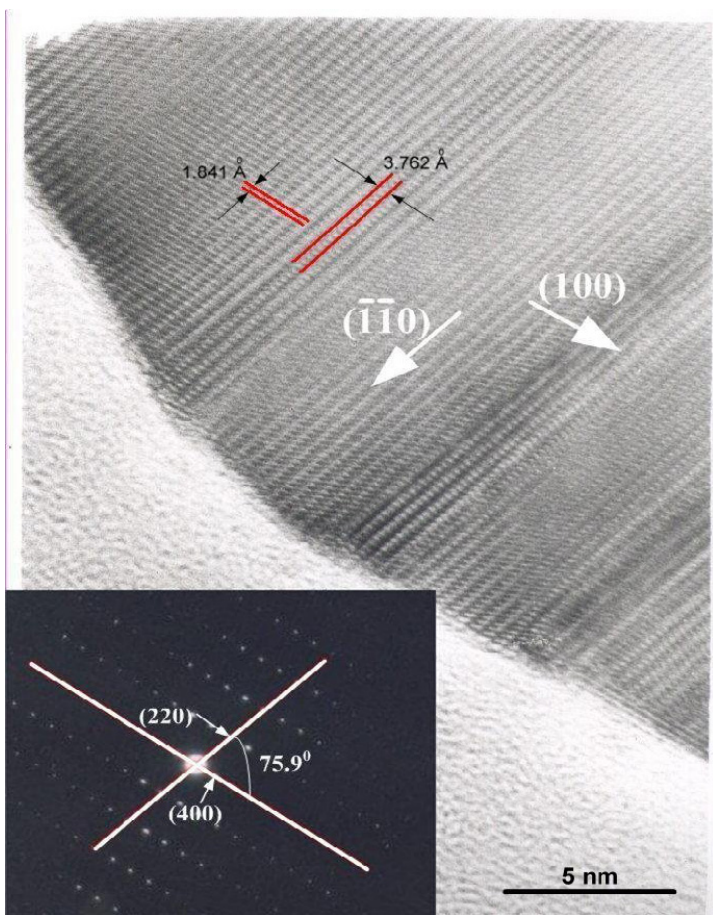

Figure 7. HRTEM image of TNTs-700W sintered at $700^{\circ} \mathrm{C}$ and the corresponding selected area electron diffraction pattern (insert).

energy between elongated planes [26-28]. Such a difference may be attributed to the intercalation of $\mathrm{Na}$ atoms within $\left(\mathrm{Ti}_{3} \mathrm{O}_{7}\right)^{2-}$ layers. Based on the topotactical connection, the coalescence of the $\left(\mathrm{Ti}_{3} \mathrm{O}_{7}\right)^{2-}$ layers forms the resulting fragments of $\left(\mathrm{Ti}_{6} \mathrm{O}_{13}\right)^{2-}$, which is expected to provide a specific elongated (chainlike) orientation. Simulating the transformation from $\mathrm{Na}_{2} \mathrm{Ti}_{3} \mathrm{O}_{7}$ to $\mathrm{Na}_{2} \mathrm{Ti}_{6} \mathrm{O}_{13}$, these chains link to each other by sharing vertices to form $\mathrm{Na}_{2} \mathrm{Ti}_{6} \mathrm{O}_{13}$ with $\mathrm{Na}$ atoms retained within the accommodation provided by $\left(\mathrm{Ti}_{6} \mathrm{O}_{13}\right)^{2-}$ units, as indicated in figure 6(b). Indirect evidence is provided by Andersson and Wadsley [29] that the $\mathrm{H}_{2} \mathrm{Ti}_{3} \mathrm{O}_{7}$ transforms topotactically into $\mathrm{H}_{2} \mathrm{Ti}_{6} \mathrm{O}_{13}$ owing to the crystalline similarities. Therefore, the structure of $\mathrm{Na}_{x} \mathrm{H}_{2-x} \mathrm{Ti}_{3} \mathrm{O}_{7}(x>1)$ is accessible to form $\mathrm{Na}_{2} \mathrm{Ti}_{6} \mathrm{O}_{13}$ following a topotactical connection process. This phenomenon also provides valid evidence for our research to assign the as-synthesized TNTs to the $\mathrm{Na}_{x} \mathrm{H}_{2-x} \mathrm{Ti}_{3} \mathrm{O}_{7}$ structure, rather than to other sodium or hydrate titanates reported in previous literature $[14,21,30] . \mathrm{Na}_{2} \mathrm{Ti}_{6} \mathrm{O}_{13}$ from TNTs-700 W sintering at $700{ }^{\circ} \mathrm{C}$ is sure to possess a higher surface energy difference between $\{400\}$ and $\{220\}$ surfaces, as indicated in figure 7 together with the corresponding electron pattern in the insert. The result is supported by the visible lattice fringes projected along [001], reflecting that the nanorods have long and short axes along the [110] and [100] directions, respectively.

\section{Conclusions}

The presented work provided evidence that the TNT structure can be rapidly achieved with the aid of microwave irradiation. The microwave induced TNTs are assigned for $\mathrm{Na}_{x} \mathrm{H}_{2-x} \mathrm{Ti}_{3} \mathrm{O}_{7}$ where the $\mathrm{Na}-\mathrm{Ti}-\mathrm{O}$ bond is favourably generated under higher microwave irradiation power. Regarding the effect of post-thermal-treatments on TNTs, TNTs-70 W with lower $\mathrm{Na}$ content transform to the anatase phase at $500^{\circ} \mathrm{C}$. They subsequently proceed with the classic anatase-to-rutile transformation to form rutile $\mathrm{TiO}_{2}$ particles at $700{ }^{\circ} \mathrm{C}$. In the case of TNTs- $700 \mathrm{~W}$ sintering at $700{ }^{\circ} \mathrm{C}$, a constituted $\left(\mathrm{Ti}_{6} \mathrm{O}_{13}\right)^{2-}$ structure results from the topotactical connection of $\left(\mathrm{Ti}_{3} \mathrm{O}_{7}\right)^{2-}$ through vertex-sharing. Na atoms are subsequently accommodated within the tunnel of $\left(\mathrm{Ti}_{6} \mathrm{O}_{13}\right)^{2-}$ to form $\mathrm{Na}_{2} \mathrm{Ti}_{6} \mathrm{O}_{13}$. Both rearrangement and topotactical connection of $\left[\mathrm{TiO}_{6}\right]$ units occurred on TNTs- $400 \mathrm{~W}$ at $700^{\circ} \mathrm{C}$ which generated the mixing of the anatase, rutile, and $\mathrm{Na}_{2} \mathrm{Ti}_{6} \mathrm{O}_{13}$ phases. In sum, microwave irradiation not only improves the formation kinetics of TNTs, but also constructs the welldefined behaviour for TNTs after thermal treatment.

\section{Acknowledgments}

The authors would like to thank the National Science Council of the Republic of China for financially supporting this research under Contract No. NSC 95-2221-E-002-143-MY3.

\section{References}

[1] Hoyer P 1996 Langmuir 121411

Liu S M, Gan L M, Liu L H, Zhang W D and Zeng H C 2002 Chem. Mater. 141391

[2] Kasuga T, Hiramatsui M, Hoson A, Sekino T and Niihara K 1998 Langmuir 143160

[3] Zwilling V, Darque-Ceretti E, Boutry-Forveille A, David D, Perrin M Y and Aucouturier M 1997 Surf. Interface Anal. 27629

Miao Z, Xu D, Ouyang J, Guo G, Zhao X and Tang Y 2002 Nano Lett. 2717

[4] Kasuga T, Hiramatsui M, Hoson A, Sekino T and Niihara K 1999 Adv. Mater. 111307

[5] Tsai C C and Teng H 2004 Chem. Mater. 164352

[6] Nian J N and Teng H 2006 J. Phys. Chem. B 1104193

[7] Poudel B, Wang W Z, Dames C, Huang J Y, Kunwar S, Wang D Z, Banerjee D, Chen G and Ren Z F 2005 Nanotechnology 161935

[8] Ding X, Xu X G, Chen Q and Peng L M 2006 Nanotechnology 175423

[9] Ma Y, Lin Y, Xiao X, Zhou X and Li X 2006 Mater. Res. Bull. 41237

[10] Zhu Y C, Li H L, Koltypin Y and Gedanken A 2001 Chem. Commun. 242616

[11] Wu X, Jiang Q Z, Ma Z F, Fu M and Shangguan W F 2005 Solid State Commun. 136513

[12] Zhang M, Jin Z, Zhang J, Guo X, Yang J, Li W, Wang X and Zhang Z 2004 J. Mol. Catal. A 217203

[13] Sun X and Li Y 2003 Chem. Eur. J. 92229

[14] Zhu H Y, Lan Y, Gao X P, Ringer S P, Zheng Z F, Song D Y and Zhao J C 2005 J. Am. Chem. Soc. 1276730

[15] Morgado E, de Abreu M A S, Pravia O R C, Marinkvic B A, Jardim P M, Rizzo F C and Araújo A S 2006 Solid State Sci. 8888

[16] Tsai C C and Teng H 2006 Chem. Mater. 18367

[17] Zhang Q, Gao L, Sun J and Zheng S 2002 Chem. Lett. 2226

[18] Chen B Q, Zhou W, Du G and Peng L M 2002 Adv. Mater. 141208

[19] Thorne A, Kruth A, Tunstall D, Irvine J T S and Zhou W 2005 J. Phys. Chem. B 1095439

[20] Du G H, Chen Q, Che R C, Yuan Z Y and Peng L M 2001 Appl. Phys. Lett. 793702

[21] Yang J, Jin Z, Wang X, Li W, Zhang J, Zhang S, Guo X and Zhang Z 2003 Dalton Trans. 203898 
[22] Nakahira A, Kato W, Tamai M, Isshiki T and Nishio K 2004 J. Mater. Sci. 394239

[23] Weng L Q, Song S H, Hodgson S, Baker A and Yu J 2006 Eur. Ceram. Soc. 261405

[24] Gouma P I, Dutta P K and Mills M J 1999 Nanostruct. Mater 111231

[25] Gouma P I and Mills M J 2001 J. Am. Ceram. Soc. 84619
[26] Jun Y W, Casula M F, Sim J H, Kim S Y, Cheon J and Alivisatos A P 2003 J. Am. Chem. Soc. 12515981

[27] Penn R L and Banfield J F 1999 Geochim. Cosmochim. Acta 631549

[28] Penn R L and Banfield J F 1998 Science 281969

[29] Andersson S and Wadsley A D 1962 Acta Crystallogr. 15194

[30] Ma R, Bando Y and Sasaki T 2003 Chem. Phys. Lett. 380577 